\title{
Article \\ The Effects of Depth-Related Environmental Factors on Traits in Acropora cervicornis Raised in Nurseries
}

\author{
Claudia Patricia Ruiz-Diaz ${ }^{1, *(D)}$, Carlos Toledo-Hernández ${ }^{1, *}$, Juan Luis Sánchez-González ${ }^{1,2}$ \\ and Brenda Betancourt ${ }^{3}$
}

Citation: Ruiz-Diaz, C.P.

Toledo-Hernández, C.;

Sánchez-González, J.L.; Betancourt, B

The Effects of Depth-Related

Environmental Factors on Traits in

Acropora cervicornis Raised in

Nurseries. Water 2022, 14, 212.

https://doi.org/10.3390/w14020212

Academic Editor: Kevin B. Strychar

Received: 9 December 2021

Accepted: 7 January 2022

Published: 12 January 2022

Publisher's Note: MDPI stays neutral with regard to jurisdictional claims in published maps and institutional affiliations.

Copyright: (C) 2022 by the authors. Licensee MDPI, Basel, Switzerland. This article is an open access article distributed under the terms and conditions of the Creative Commons Attribution (CC BY) license (https:// creativecommons.org/licenses/by/ $4.0 /)$.
1 Sociedad Ambiente Marino (SAM), San Juan 00931-2158, Puerto Rico; juan.sanchez2@upr.edu 2 Department of Biology, University of Puerto Rico, San Juan 00931-3360, Puerto Rico

3 Department of Statistics, University of Florida, Gainesville, FL 118545, USA; bbetancourt@ufl.edu

* Correspondence: claudiapatriciaruiz@gmail.com (C.P.R.-D.); cgth0918@gmail.com (C.T.-H.)

\begin{abstract}
Populations of Acropora cervicornis, one of the most important reef-building corals in the Caribbean, have been declining due to human activities and global climate change. This has prompted the development of strategies such as coral farms, aimed at improving the long-term viability of this coral across its geographical range. This study focuses on comprehending how seawater temperature (ST), and light levels (LL) affect the survival and growth of A. cervicornis fragments collected from three reefs in Culebra, Puerto Rico. These individuals were fragmented into three pieces of the similar sizes and placed in farms at 5, 8, and $12 \mathrm{~m}$ depth. The fragments, ST and LL were monitored for 11 months. Results show that fragments from shallow farms exhibit significantly higher mortalities when compared to the other two depths. Yet, growth at shallow farms was nearly $24 \%$ higher than at the other two depths. Corals grew fastest during winter, when temperature and LL were lowest, regardless of the water depth. Fragment mortality and growth origin were also influenced by reef origin. We conclude that under the current conditions, shallow farms may offer a slight advantage over deep ones provided the higher growth rate at shallow farms and the high fragment survival at all depths.
\end{abstract}

Keywords: restauration; coral farm; Acropora cervicornis; sea temperature; light levels

\section{Introduction}

The degradation of Caribbean coral reefs has reached unprecedented rates. It is estimated that nearly $80 \%$ of the Caribbean reefs have been lost, while the remaining $20 \%$ are seriously threatened [1-3]. The scientific community's consensus for the observed declines points towards human-related activities such as extensive sedimentation and nitrification [4,5], the unsustainable exploitation of shellfish and fish resources [6]; and more recently, the increase in seawater temperature, ocean acidification, light levels, and coral diseases [7-12]. These factors, acting alone or synergistically, have diminished the natural capacity of corals to recover $[13,14]$.

The significant reduction in the staghorn coral Acropora cervicornis in its natural habitat is, perhaps, the best example of the current situation of reef-building corals in the Caribbean. Historically, A. cervicornis was one of the most dominant and essential reef-builder coral species in the Caribbean [15]. Its broad vertical distribution, i.e., from a 1 to $30 \mathrm{~m}$ depth [16], high branching rates, and impressive asexual proliferation due to branch fragmentation [17] allowed this species to dominate vast areas of the reefscape. These so-called "thickets" also provided the necessary structural complexity to sustain a high diversity of fishes, invertebrates, algae, and microbial organisms [18-20].

However, during the 1980 s and 1990 s, over $90 \%$ of $A$. cervicornis populations throughout the Caribbean basin died to disease outbreaks and temperature-associated bleaching $[4,10,12,21]$. Furthermore, during the following decades, the effects of coastal-water 
degradation, coupled with the increased frequency of bleaching and outbreak events, hampered the natural capacity of $A$. cervicornis to recover, placing the surviving populations in jeopardy $[3,21]$.

To provide some protection to the surviving populations, A. cervicornis has been included in the United States Endangered Species Act (50CFR223), and the IUCN Red List of Threatened Species [22]. Even though these conservation measures have provided some level of protection, these alone have had little success at preventing further declines [23]. Consequently, implementing interdisciplinary strategies, such as coral farming, that directly impact $A$. cervicornis populations across its entire range are imperative $[17,24]$.

Coral farming has gained recognition as one of the primary strategies to restore depleted populations of A. cervicornis [24,25]. Presently, over 15 countries and islands across the wider Caribbean, including Puerto Rico, have successfully implemented coral gardening operations, primarily using A. cervicornis fragments as the main species [23]. The rationale behind this strategy is that the survival and growth of coral fragments during the farming stage are significantly higher than those of recently fragmented or recently settled corals in the wild $[15,23]$. Therefore, maintaining coral fragments in farms until they reach a safe size ( $>15 \mathrm{~cm}$ in length) will dramatically improve survival, accelerate population recovery and, consequently, restore A. cervicornis' ecological functions [26].

Nearly 30 years after implementation [27], coral farming has been the subject of extensive research addressing a diverse array of topics, including nursery designs (e.g., fixed versus floating midwater farm units) [28,29]; the effect of coral propagule size on survival and growth [30-32]; the effects of genotypic lineage on the survival and growth of coral propagules [29-32]; and the impacts of nutrients and sediment loads [30], algal competition and predation on coral propagule survival and growth, among others $[25,29,33]$. Together, these studies have helped provide better practices for coral population enhancement initiatives.

Nevertheless, aspects such as the influence of depth-related seawater temperature (ST) and Light Levels (LL) on the performance of coral fragments that are still in the farming stage, have been overlooked [32,34]. Such information is central for coral farm practitioners to understand how coral fragments being reared will respond to stochastic fluctuations in ST and LL. In this study, we sought to understand the impacts of seasonal changes in depth-related ST and LL on the survival and growth rate of A. cervicornis fragments during the farming stage. We collected $150 \mathrm{~A}$. cervicornis fragments from three distinct reefs (fifty fragments per reef) and further fragmented them into three similar small pieces ( $\approx 15 \mathrm{~cm}$ in length), which were set at three depths: $5 \mathrm{~m}, 8 \mathrm{~m}$, and $12 \mathrm{~m}$. We then recorded the survival and total linear extension at monthly intervals for eleven months. Given the great sensitivity of $A$. cervicornis corals to changes in ST and LL [6], which often cause bleaching stress, and given that the intensity and variation of these environmental factors most likely decline with water depth [35], we hypothesized that thermal and light levels stresses and subsequent mortality, should increase from deeper to more shallow waters. We also hypothesized that the growth rate of fragments in the shallower water will be higher than fragments from deeper water and higher during the summer months, given the high dependence of $A$. cervicornis on light [36]. We will conclude by providing useful recommendations to coral gardening practitioners based in our results.

\section{Materials and Methods}

\subsection{Study Site}

The study was conducted in the Punta Soldado Reef (PTS), Culebra Island, Puerto Rico. PTS is a small bay, approximately $1 \mathrm{~km}$ in width, located at the southern-most part of Culebra, Figure 1. PTS is bordered by a primary subtropical dry forest with no permanent human settlements and no agricultural activities or major runoffs flowing into the coast; consequently, near-shore waters are clear year-round. PTS has a relatively shallow fringing coral reef along its coastline extending up to $60 \mathrm{~m}$ off the coast. Sea bottom is predominantly sand, gently increasing in deep toward the open water. Its reefscape is dominated by Porites spp., Orbicella spp., Pseudodiploria spp., Millepora spp., A. cervicornis, and members of 
the Plexuridae and Gorgonacea families [26]. Zones deeper than 5-6 $\mathrm{m}$ feature a sandy bottom dominated by the invasive seagrass Halophila stipulacea and, to a lesser extent, by macroalgae such as Penicilus spp., Udotea spp., and Gracilaria spp., among other.

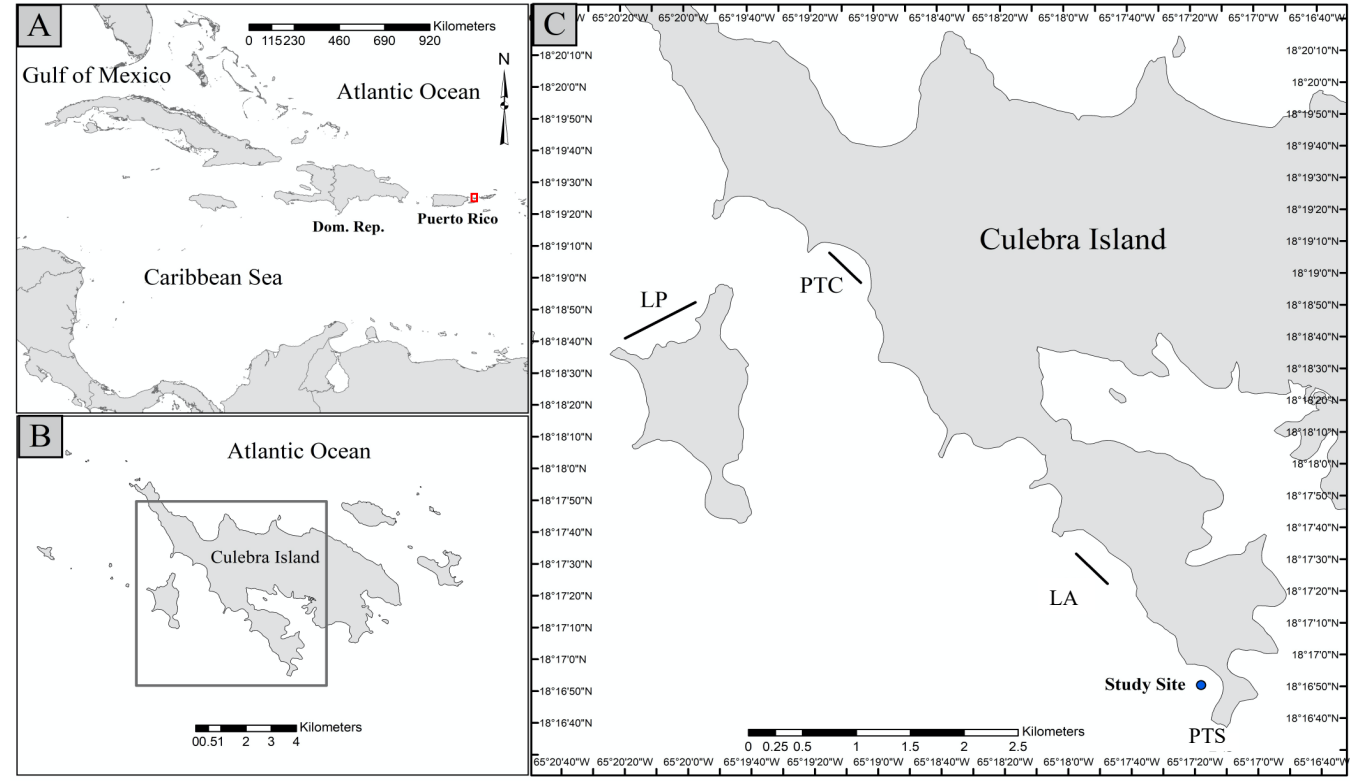

Figure 1. Map of Culebra illustrating its geographic location with respect to the Caribbean Region $(\mathbf{A}, \mathbf{B})$. The red frame in panel A indicates the location of Culebra Island, and sites of fragment collection and location of the coral farms (C). Collection sites: Luis Peña (LP), La Ahogá (LA), and Punta Tamarindo Chico (PTC); farming locations: Punta Soldado (PTS). Lines at collection sites represent the distance traveled during the fragment collections.

\subsection{Coral Collection and Gardening}

In June 2016, 150 coral fragments (50 fragments per collection site), from different A. cervicornis with no visible signs of disease were used as donor colonies. These colonies were located at the Punta Tamarindo Chico (PTC), La Ahogá (LA), and Luis Peña (LP) reefs, Figure 1C. In general, the three donor sites are reef/hard ground habitats with similar coral cover (i.e., 20-30\%). LP shows less rugosity and a higher abundance of octocorals than PTC and LA. Meanwhile, LA is more exposed to swells from the southwest than PTC and LP and is the less visited by tourists of the three donor sites. On the other hand, PTC receives higher tourist visits that the other two donor sites, given its accessibility by land and sea. However, none of the donor sites have significant runoff flow or permanent human settlement. Consequently, water clarity is well over $20 \mathrm{~m}$ years around. In addition, these sites are at least $1.2 \mathrm{~km}$ apart from each other, with a sandy bottom separating them. Therefore, we presumed that there was low or no asexual recruitment among these coral populations and therefore colonies from each site potentially had different genetic lineages. Within each site, donor colonies were found at depths ranging from 1 to $6 \mathrm{~m}$ and were more than $15 \mathrm{~m}$ apart to increase the likelihood of finding genetically distinct individuals. After collection, fragments were brought to the vessel and were submerged in three-57 L plastic baskets filled with seawater. To minimized transportation stress, fragments were completely submerged in seawater and shaded from the sun until reaching the experimental sites i.e., PTS. Once in PTS every colony was further fragmented into three pieces, each of $\sim 15 \mathrm{~cm}$ in length (hereafter named "clonal fragments"), tagged with a unique number and photographed. Tagged clonal fragments from the same donor colony were deployed to coral farms installed at three different water depths: $5 \mathrm{~m}$ (shallow), $8 \mathrm{~m}$ (medium), and $12 \mathrm{~m}$ (deep) Figure 2. Coral farms were constructed by hammering six metal rods, each $2 \times 0.02 \mathrm{~m}$, to the sandy bottom, forming a five-pointed star with one central rod and the remaining five rods (hereafter the "peripheral rods") set $2 \mathrm{~m}$ apart from the central rod, 
Figure 3A-C. The peripheral rods were connected to the central rods by two sets of fishing line, one at $1.5 \mathrm{~m}$ above the sandy bottom and the other at $1.0 \mathrm{~m}$. In total, nine five-pointed star coral farms were installed, three per depth. Coral farms at each depth were set 20-30 m apart from each other. A total of 50 fragments per farm were attached to the fishing lines for a grand total of 450 fragments. Notice that every donor colony have a clone fragment at each depth and that no more than one clonal fragment from the same donor colony was placed at the same depth, Figure 2.

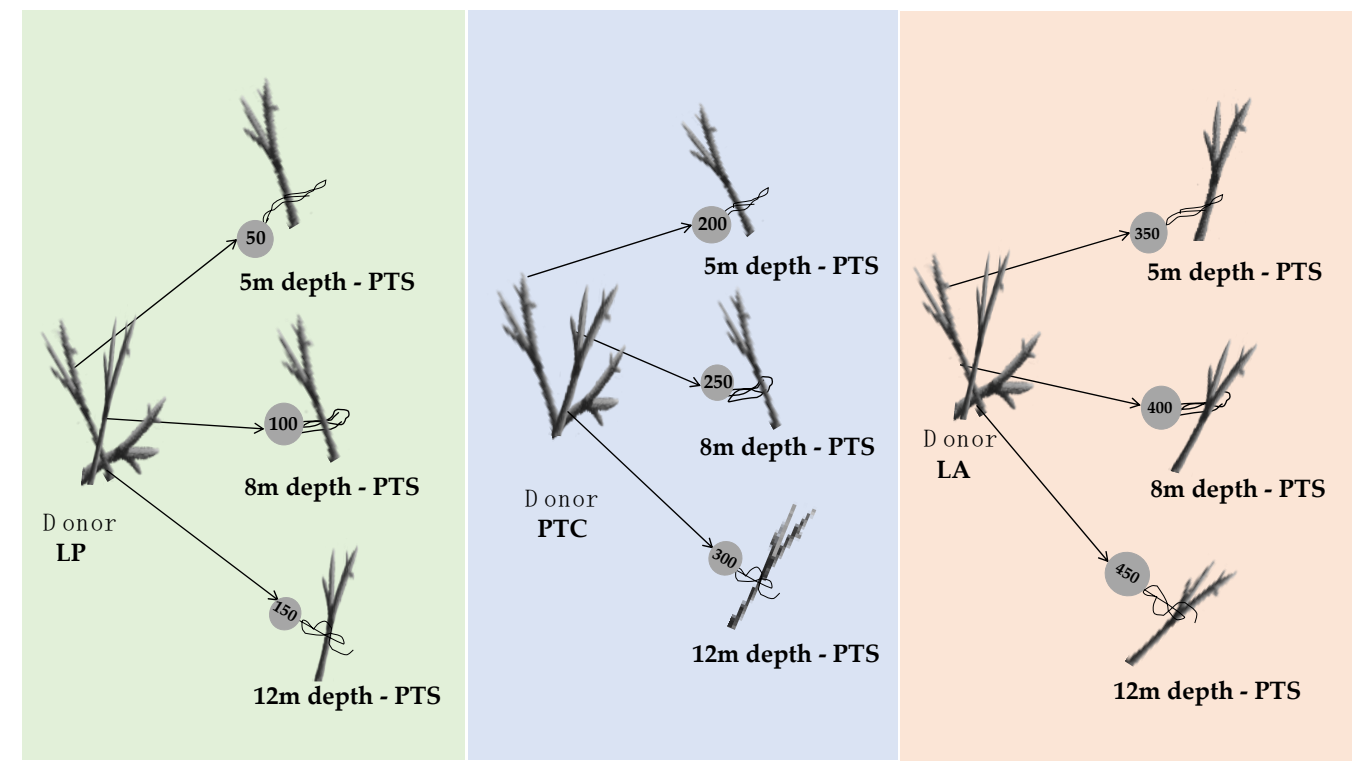

Figure 2. Diagram showing the experimental design procedures. Following colony collection from Luis Peña (LP), La Ahogá (LA), and Punta Tamarindo Chico (PTC), each donor colony was further divided into three fragments of similar length (clone fragment), tagged with a unique number, and set at a coral farm at 5, 8, and $12 \mathrm{~m}$ depths in Punta Soldado (PTS) so as only each donor coral have only one representative at each depth.

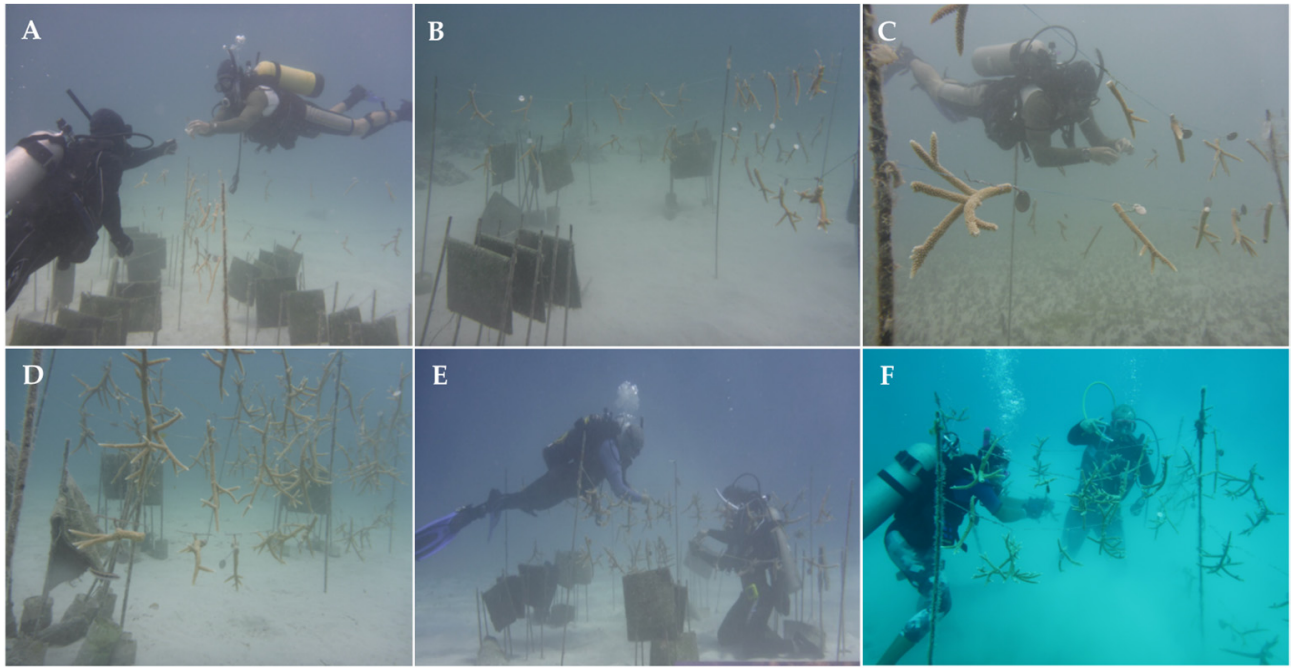

Figure 3. Installation and Maintenance of farms. Images $(\mathbf{A}-\mathbf{C})$ show the installation procedures from farms at 5, 8 and $12 \mathrm{~m}$ depths during June 2016. Images (D-F); show maintenance procedures from farms at 5, 8 and $12 \mathrm{~m}$ depths during April 2017.

\subsection{Environmental Measurements}

Seawater temperature (ST) and the relative Light Levels (LL) were measured by deploying a Hobo Pendant temperature/light data loggers 64k-UA-002-64 (Onset Company, 
Tokyo, Japan) per depth. Each device was secured to the central rod of a coral farms following the manufacture instructions. The ST and LL devices were programmed to record one datum every $15 \mathrm{~min}$. Temperatures were left to record for 30-40 days, whereas LL was recorded only the first 10 days after been deployed, as algae and sediments could interfered with the detection of light after the 10-days period. The devices were retrieved monthly and replaced with new ones. Statistical differences between month/depths (independent variables) and ST and LL (dependent variables) were explored using two, two-way ANOVA.

\subsection{Survival Analysis}

Two Kaplan-Meier survival tests (KM) with a log-rank analysis were performed to compare the survival curves among (1) clonal fragments placed at different depths, i.e., at 5, 8, and $12 \mathrm{~m}$, and (2) fragments collected from PTC, LP, and LA. These analyses were conducted under the null hypothesis of there being no differences in survival among the depths and sites of fragment collections. For the depth-comparison analysis, samples from the same water depth were pooled as a group regardless of their collection origin. Similarly, to detect potential differences in fragment mortality based on the site of fragment collection, samples from the same site of collection were grouped, regardless of the depth at which they were placed. The time lapse for these analyses ran from July 2016 to June 2017. To estimate the KM survival test, we first estimate the death probability at a specific month. That is, the total number of dead individuals recorded during a mortality event at a given month, divided by the number of individuals surviving during that mortality event. We estimated the probability of survival during that specific month by subtracting the death probability during that month from one. Finally, the monthly survival probability was estimated by multiplying the survival probability, calculated for each specific mortality event until that time. These statistical analyses were carried out using the survival package version 2.38 in $R$ [37].

\subsection{Monthly Growth Rates}

At monthly intervals from July 2016 to June 2017, coral farms were visited to remove fouling organisms such as filamentous algae that could potentially harm the clonal fragments, Figure 3D-F. Additionally, in situ photographs (scale-by-site) were taken to estimate total length extension (TL) to the nearest $\mathrm{cm}$, using Coral Point Count software with Excel extensions (СPCe) [38], Figure 4. Coral fragments were photographed from different angles to ensure that length extension of branches from each clone fragment were fully appreciated. The monthly TL estimates were calculated by summing all branches whose length was greater than $0.5 \mathrm{~cm}$. The TLs were then transformed to the monthly coral growth rate (MGR) by subtracting the most recent TL measurement from the previous TL measurement, divided by the number of days between monitoring periods. The subsequent analysis was performed only with coral individuals whose three clonal fragments remained alive by the end of the study, i.e., 135 coral individuals in total.
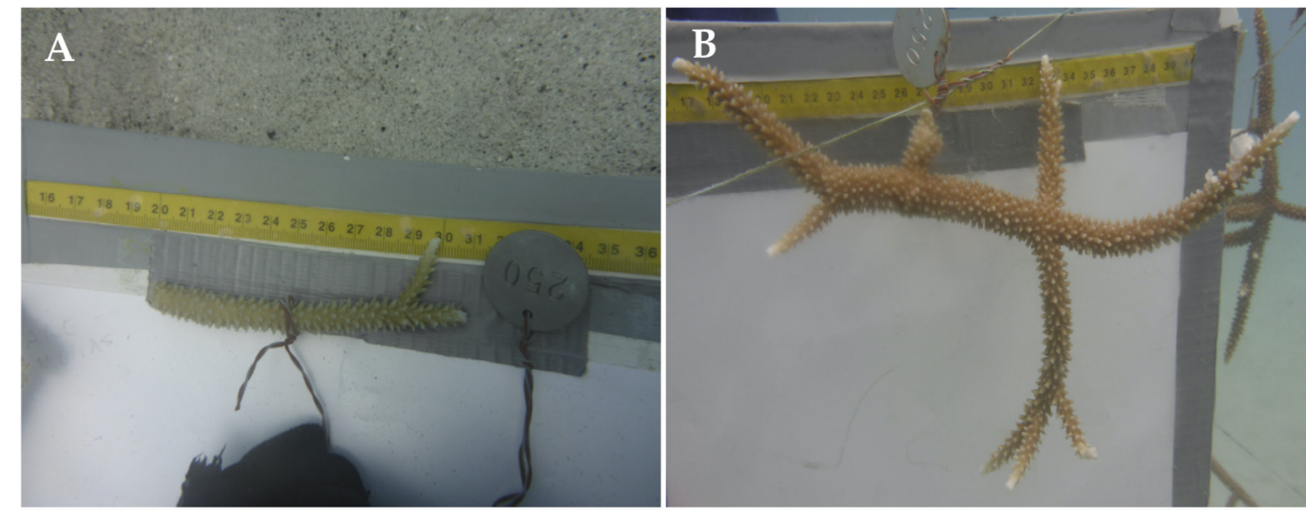

Figure 4. Cont. 

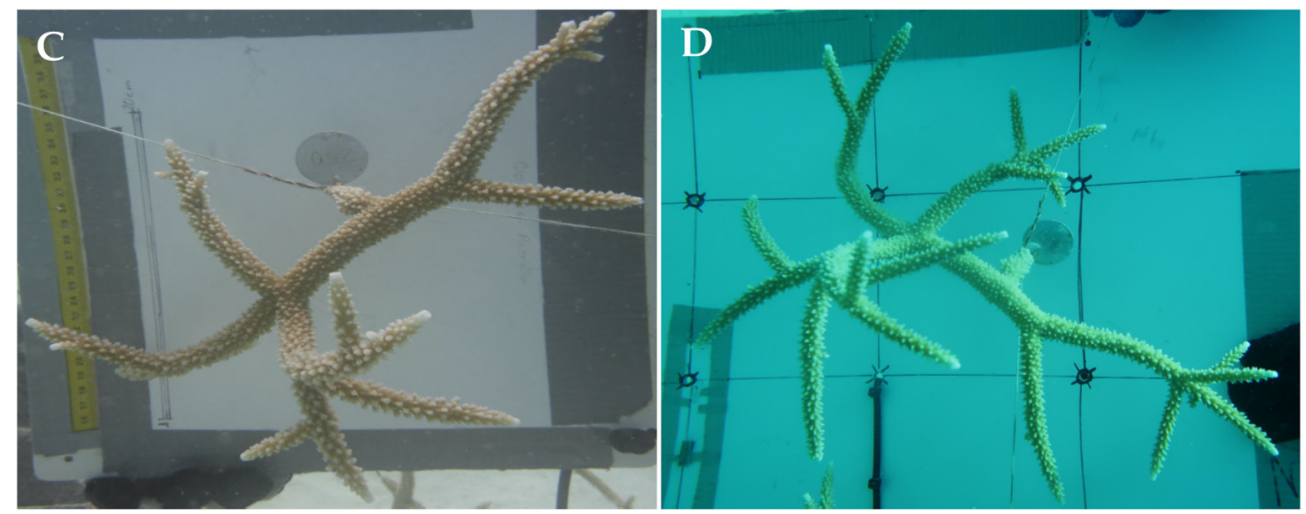

Figure 4. Clone fragment number 250 followed through time. Image of clone fragment 250 before hanged on farm in June 2016 (A), and image showing the same coral in December 2016 (B), March 2017 (C) and June 2017 (D).

\subsection{Coral Growth Analysis}

For the implementation of the statistical model, the Month variable was treated as a numeric variable, which reflects the assumption that the relationship between the growth rate and the Month is linear. This choice is based on exploring the growth profiles of the clonal fragments across depths, collection sites and months.

To evaluate the effects of depth-related variability in ST and LL, and the collection sites on the growth rate of clonal fragments across time, we created a linear mixed model (LMM) with a random effect analysis. The model included the fixed effects of (1) the categorical variables of depths and collection site, each with three levels, i.e., shallow, medium, and deep, and PTC, LP, and LA, respectively; (2) the continuous variables of ST and LL; (3) Months; (4) first-order interactions between all variables except Months; and (5) second-order interactions of ST and LL with depth and collection site, respectively. The model also includes random intercepts and random slopes associated with the Month variable for each coral to consider possible MGR variability on average and over time. For this analysis, we standardized all numeric predictors i.e., ST, LL, Months, and the response variable i.e., MGR by subtracting the overall mean divided by the respective standard deviation. The final model structure was specified through backward stepwise selection, starting with the saturated model's random components, and followed by the fixed effects, excluding terms that were not significant, in a hierarchical fashion. The relevant model components were selected by performing $\chi^{2}$ tests to compare nested models that only differ in the term of interest. This implies choosing the more saturated model only if the reduction in the residual sum of squares was statistically significant compared to the simpler model. The statistical analyses in this study were performed using the lmerTest package in $\mathrm{R}[39,40]$.

\section{Results}

\subsection{Environmental Measurements}

\subsubsection{Temperature}

Seawater temperature across all depths showed a similar pattern of variation throughout the study period, Figure 5A. At all depths, the highest average temperature values were recorded from July to September 2016 (summer), then decreased from October to December 2016 (fall), reaching the lowest values from January to March 2017 (winter), and rising again from April to June 2017 spring: Figure 5A. Nevertheless, the monthly average ST was consistently higher and more variable at a $5 \mathrm{~m}$ depth than at 8 and $12 \mathrm{~m}$ depths. The highest recorded value $\left(31.47^{\circ} \mathrm{C}\right)$ at this depth occurred in September 2016. Meanwhile, the lowest monthly average ST values were consistently recorded at a $12 \mathrm{~m}$ depth, with the lowest values $\left(25.7^{\circ} \mathrm{C}\right)$ occurring in March of 2017, Figure 5A. Intermediate monthly average ST values were recorded at all depths in the fall and spring months, the values 
at $8 \mathrm{~m}$ depth during spring 2017 being slightly higher than at the rest of the other depths. These differences were statistically significant, Table 1.
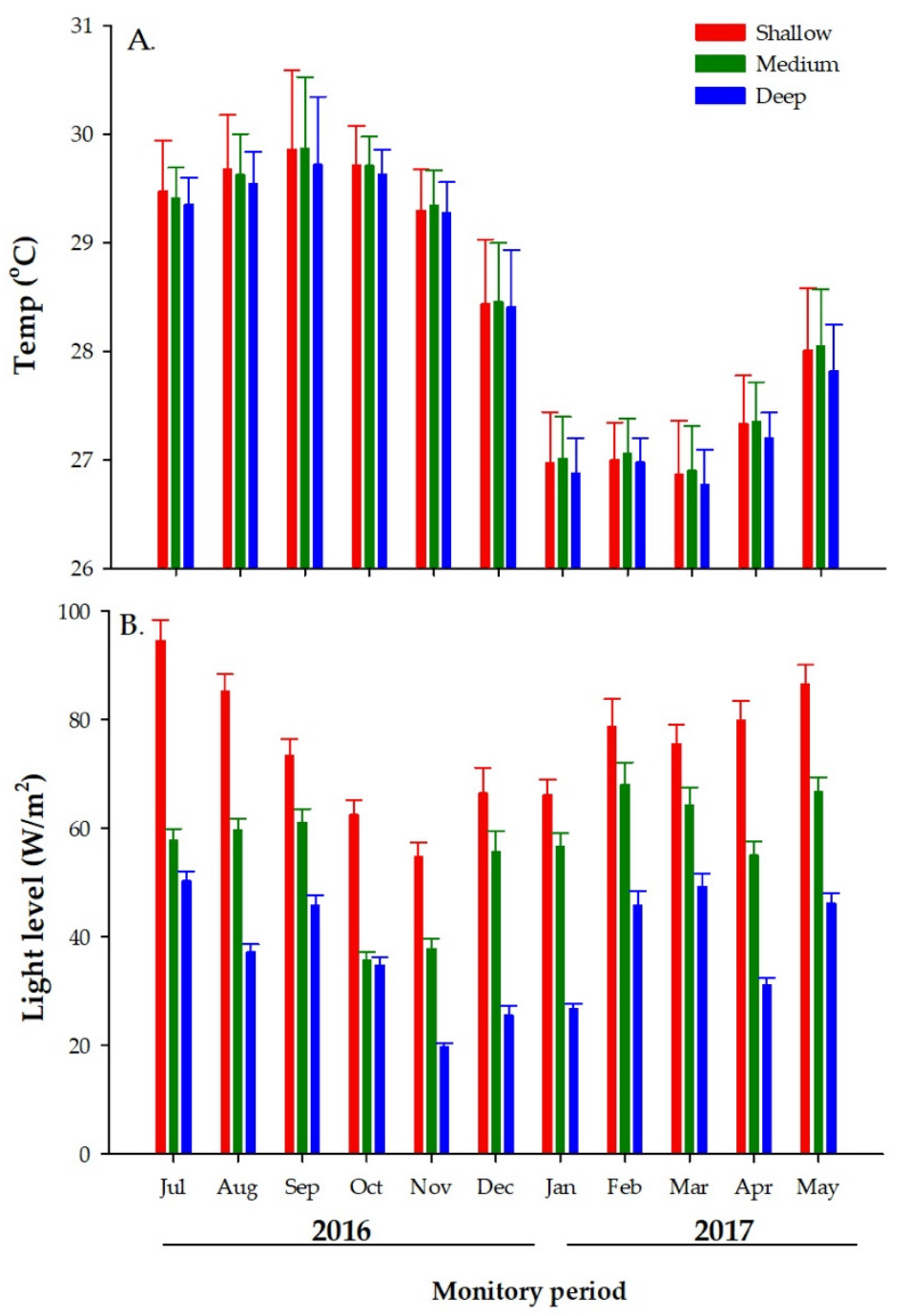

Figure 5. Comparison of temperatures (A), and (B) light levels (measured during the first ten days of every month), from farms set at shallow ( $5 \mathrm{~m}$, in red), medium ( 8 , in green) and deep (12 $\mathrm{m}$, in blue) depths. Bars represents monthly average and whiskers standard error.

Table 1. Two-way ANOVAs results between Seawater Temperature (ST) and Light Level (LL). ** and *** represent levels of significance.

\begin{tabular}{cccc}
\hline Variable & Df & $\boldsymbol{F}$ Value & $p$-Value \\
\hline Temperature ${ }^{\circ} \mathrm{C}$ & & & \\
Month & 10 & 2881.47 & $2 \times 10^{-16 * * *}$ \\
Depth & 2 & 35.95 & $1 \times 10^{-5 * *}$ \\
Light Levels $\left(\mathrm{W} / \mathrm{m}^{2}\right)$ & 10 & 7.79 & $5.61 \times 10^{-5 * *}$ \\
Month & 2 & 103.25 & $2.88 \times 10^{-11 * *}$ \\
Depth & &
\end{tabular}

\subsubsection{Light Levels}

LL showed a trend similar to that of temperature with LL being consistently higher at $5 \mathrm{~m}$ depth than at 8 and $12 \mathrm{~m}$ depth. The LL at a $12 \mathrm{~m}$ depth was the lowest and least variable when compared to the other depths, Figure 5B. However, each depth exhibited different LL patterns across time. At $5 \mathrm{~m}$ depth, for instance, the highest LL values were observed in July 2016, then decreased linearly, reaching lowest values in November 2016 
and thereafter, increasing again Figure 5B. By contrast, the monthly averages of LL at 8 and $12 \mathrm{~m}$ depths exhibited slightly different patterns. At $8 \mathrm{~m}$ depth, LL exhibited discrete but continued increments from July-September and then dropped to its lowest recorded value in October. Thereafter, LL steadily increased reaching its highest value in February. LL dropped again over the following two months, then increasing once again during May. Mean monthly LL at $12 \mathrm{~m}$ also showed similar trend as that of $8 \mathrm{~m}$, although slightly dropped during August, Figure 5B. These differences were statistically different, Table 1.

\subsubsection{Survival}

Overall, 426 out of the 450 fragments survived during the study period. Survival varied across time and depths. Of the 24 recorded total fragment fatalities, eight occurred during the first 30 days of the study (i.e., from June to July 2016), three in the shallow nurseries, four at medium depth, and one in the deeper nurseries. This was the only time interval across the study period exhibiting mortalities of clonal fragments at all three depths. Overall, fragment mortality increased from deep to shallower farms, with mortalities in shallow farms double the mortalities recorded at medium-depth farms and quadruple the mortalities in deeper farms, Figure 6A. Likewise, mortalities in the medium-depth farms doubled those of the deepest farms. These differences in survival between depths were statistically significant $\left(\chi^{2}=8.2, \mathrm{df}=2\right.$, and $p$-value $=0.0$, Figure $\left.6 \mathrm{~A}\right)$. Mortality also varied by collection site. Fifteen of the 24 recorded mortalities were fragments from PTC. Of the remaining nine mortalities, four were fragments collected at LP and five from LA. These differences were also statistically significant $\left(\chi^{2}=10.2, \mathrm{df}=2 ; p\right.$-value $=0.006$, Figure $\left.6 \mathrm{~B}\right)$.

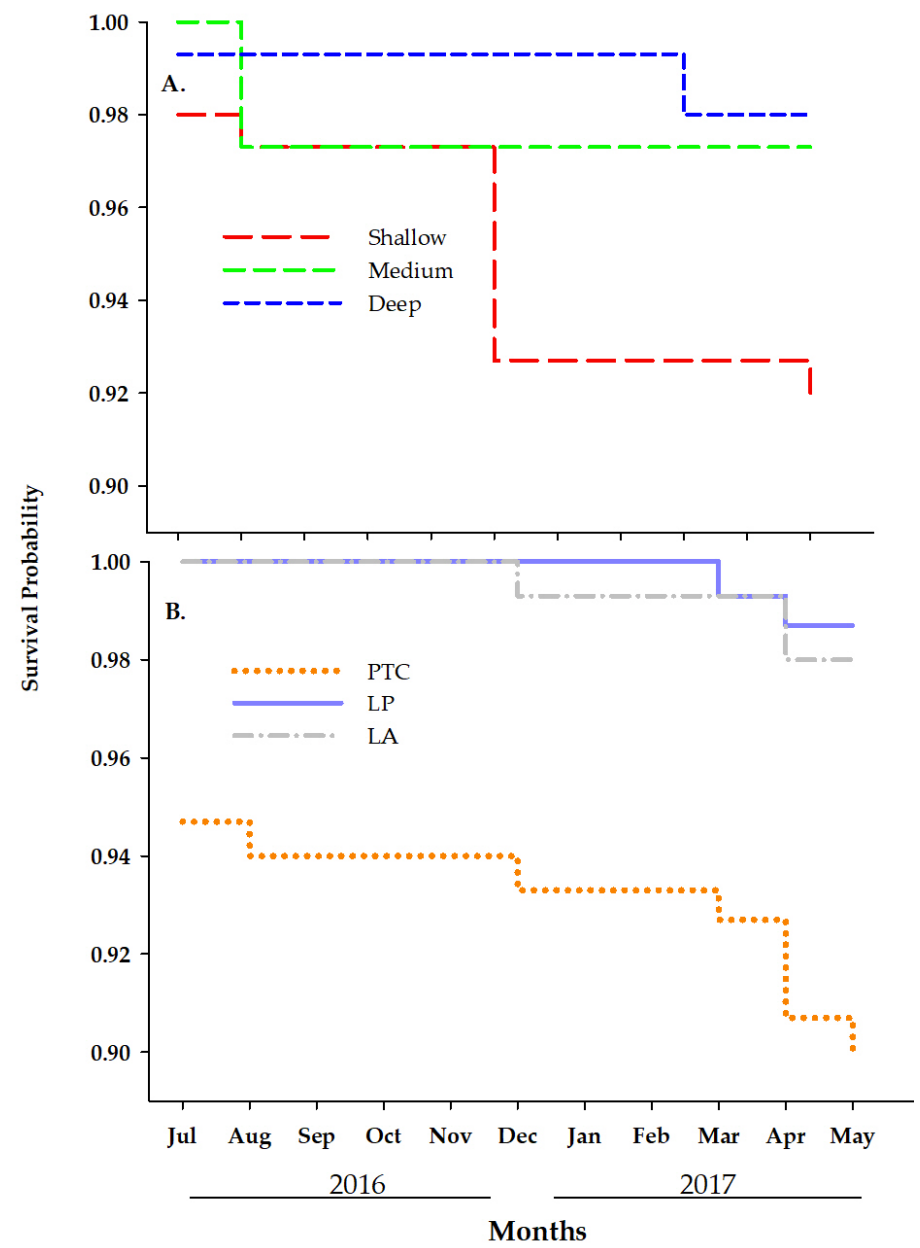

Figure 6. Probability of surviving of Acropora cervicornis fragments across the 11-month study period by depths (A) and site of collection (B): Luis Peña (LP), La Ahogá (LA) and Punta Tamarindo Chico (PTC). 


\subsection{Monthly Growth Rate (MGR) of Colonies}

All the fixed-effect terms from our LMM were significant at 5\% (Table 2). However, the most relevant results can be summarized as follows: (1) The model shows a strong proportional inverse effect between ST and LL and the average MGR from clonal fragments at all depths. That is, when ST and LL decreased, MGR increased. (2) The model also showed that the mean MGR from fragments at all depths correlated positively with the month, as the mean coral fragments' monthly growth was always above zero. This suggests that there were no major unexpected fragmentations, i.e., strong groundswells. Moreover, the observed negative estimate at medium and deep-water farms suggests that corals in shallow-water farms have higher average MGRs than at the other two farm depths, Table 2. However, MGR varied across months, with higher mean MGRs from November 2016 to March (the coldest months of the study period) and lower MGRs from July to October 2016 and April to June 2017, Figure 7A. (3) The model also indicates that the mean MGRs varied by collection site ("Locally", Table 2). Higher MGRs from clonal fragments collected at PTC was observed when compared to the MGRs from fragments collected at LP and LA. This result was further confirmed after grouping colonies by the site of collection, farm depth, and whether the MGR of each fragment was above or below the overall mean MGR calculated by each depth $\left(\chi^{2}=8.4851, \mathrm{df}=2, N=61, p<0.05\right)$, Figure 7B.

Table 2. Linear Mixed Model (LMM) results fit by maximum likelihood $t$-tests using Satterthwaite. ** and ${ }^{* * *}$ represent level of significance.

\begin{tabular}{cccc}
\hline Model Variable (Fixed Effects) & Estimate & $t$ Value & $p$ \\
\hline Intercept & -0.214 & -2.796 & $0.005^{* *}$ \\
Month & 0.056 & 4.824 & $1.4 \times 10^{-6 * * *}$ \\
Depth Deep & -0.186 & -2.781 & $0.005^{* *}$ \\
Depth Medium & -0.275 & -4.917 & $9.15 \times 10^{-7 * * *}$ \\
Temperature & 0.303 & -5.375 & $8.06 \times 10^{-8 * * *}$ \\
Light Levels & -0.121 & -2.585 & $0.009^{* *}$ \\
Locality PTC & 0.185 & 3.324 & $0.001^{* *}$ \\
Locality LA & 0.14 & 2.734 & $0.006^{* *}$ \\
Temperature: PTC & -0.123 & -3.08 & $0.002^{* *}$ \\
Temperature: LA & -0.169 & -4.608 & $4.44 \times 10^{-6 * * *}$ \\
Temperature: Light Level & 0.177 & 2.81 & $0.005^{* *}$ \\
Deep: Temperature & 0.26 & 2.876 & $0.004^{* *}$ \\
Medium: Temperature & 0.279 & 4.315 & $1.64 \times 10^{-5 * * *}$ \\
Deep: Light Levels & 0.252 & 4.208 & $2.63 \times 10^{-5 * * *}$ \\
Medium: Light Levels & 0.311 & 5.108 & $3.41 \times 10^{-7 * * *}$ \\
Deep: Temperature: Light Levels & -0.244 & -3.395 & $0.00067^{* * *}$ \\
Medium: Temperature: Light Level & -0.368 & -4.765 & $1.96 \times 10^{-6 * * *}$ \\
\hline
\end{tabular}

Finally, the model revealed that clonal fragments' MGR (i.e., the monthly growth rate of the three fragments from an individual coral, set at different depths) varied across months, with a $\chi^{2}=120, p$ value $=2 \times 10^{-14}$ (Random effects). In other words, these results showed there were fragments from the same donor colony with above average MGRs at all depths. Similarly, there were fragments from the same donor colony showing below average MGRs at all depths, and fragments that showed above average MGRs in one depth and below average in other depths. 


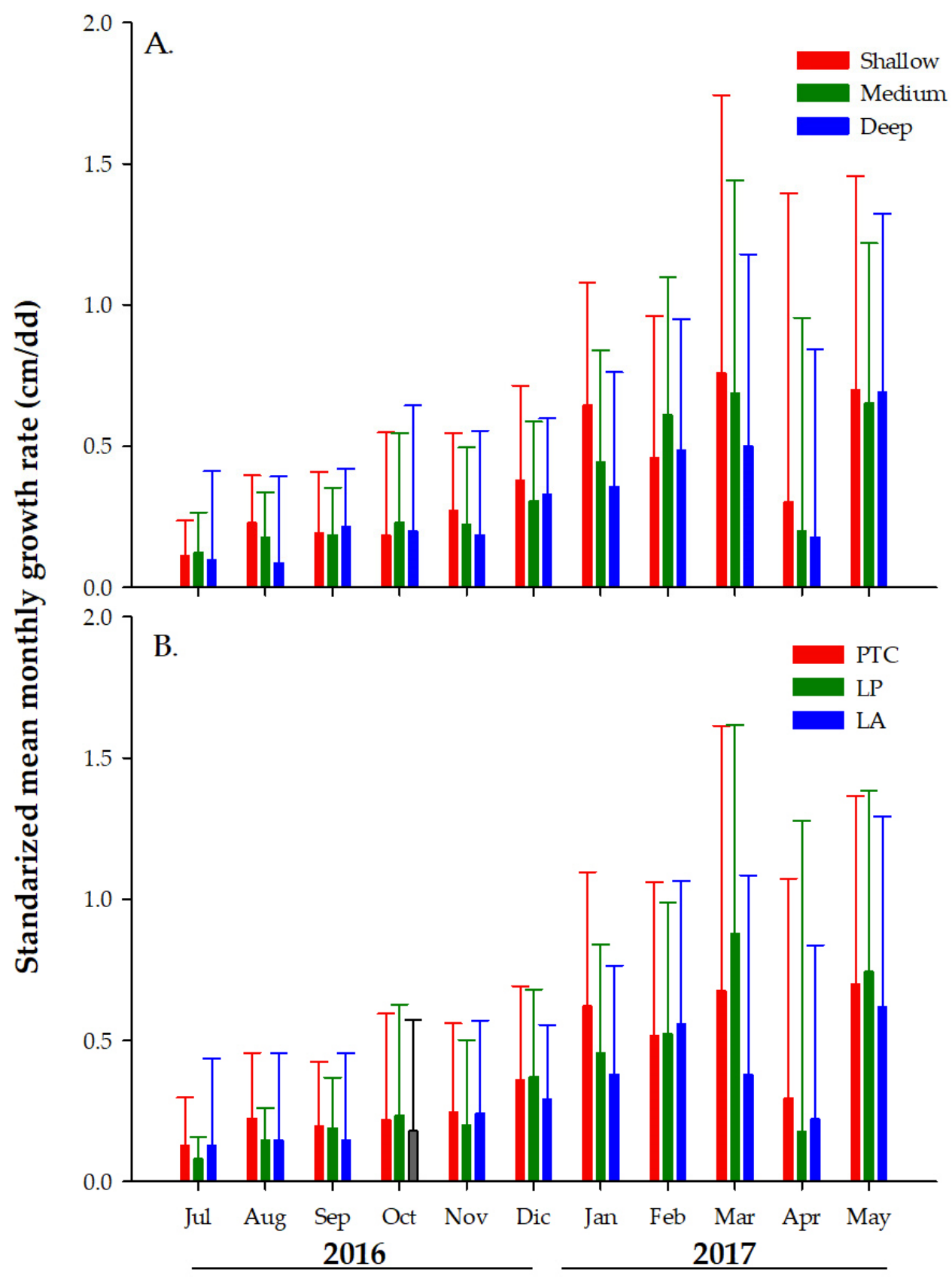

Figure 7. Comparison of the monthly growth rate of Acropora cervicornis fragments by farm depth (A) and site of fragment collection (B). Punta Tamarindo Chico (PTC), Luis Peña (LP), and La Ahogá (LA). $N=135$ fragment individuals per depth/site. Bars represents monthly average and whiskers standard error.

\section{Discussion}

Coral vulnerability to common stressors such as temperature and light levels are expected to increase under current climate change scenarios. One strategy to reduce the impacts of these climate-change-related factors is to migrate to areas with more favorable environmental conditions. Given that the seawater temperature is often lower in deeper waters and light levels declines with depth, the stress induced by these factors should similarly decline. In fact, this pattern has been extensively reported in the scientific literature, but with some controversy [41-43].

Coral farming operations are not immune to these climate change issues and moving coral farms from shallow to deeper water may be a feasible strategy for lowering the risk of 
losing fragments to unforeseen high temperature and light events. However, this strategy has not been thoroughly studied based on fragments mortality, growth, and costs across time Therefore, this study assessed the effects of water-depth-related temperature and light levels on the growth and mortality of coral fragments collected from different sites and further compared these results across time.

Provided that the main goal of coral farm operations is to optimize the survival and swift growth of coral, we will discuss three major findings that could improve coral farming operations. (1) The prevailing water temperature and light levels across depth and time, have contrasting impacts on the mortality and growth of coral fragments. (2) The collection site plays an important role in the survival and growth rates of coral fragments and (3) the magnitude by which these factors affect the mortality and growth rate are colony specific.

Our study showed that the fluctuation in ST and LL across time and depth seem to have negligible effects on fragment mortality, given the overall low mortality $(\approx 5 \%)$ recorded during the eleven months of the monitoring period.

Mortality in this study, did not follow a clear seasonal pattern, in the absence of noticeable environmental stress. However, several conclusions should be highlighted. First, survival was lower during the first 30 days, i.e., June to July 2016, as one-third of the total mortalities $(8 / 24)$ were recorded during these days. Akin to a previous study [25], early mortality may be the result from stress caused by fragment manipulation. Alternatively, UV/blue light shocks may also produce some mortality, especially to corals collected at deeper areas and deployed in shallower farms. Nonetheless, in different periods after the conclusion of this study, we have outplanted over 400 fragments onto shallow reefs (e.g., 2 to $5 \mathrm{~m}$ depth), all of which have been harvested from farms at $12 \mathrm{~m}$ depth and the survival estimates are nearly $98 \%$ seven months after being outplanted. Therefore, further research must be conducted to fully understand effect of the different forms of radiation on coral fragments.

Secondly, mortality was higher in farms set at shallow depths and decreased in deeper farms. Nearly 59\% of deaths occurred in the shallower farms. Moving into deeper water, mortality decreased from $30 \%$ in farms set at an $8 \mathrm{~m}$ depth to $12.5 \%$ mortality in the deeper farms. These results suggest that fragments in the deeper farms may have suffered less stressful conditions than fragments set in the shallower farms. Nonetheless, mortality at shallow water was still well above the benchmarks proposed by [44]. Other studies have reported results similar to ours, arguing that corals in deeper zones would be better protected from damaging water-temperature and light-intensity levels, thereby improving their survival with respect to corals in shallower zones [45-47]. Thirdly, mortality was higher in fragments collected at PTC when compared to fragments collected at LP and LA, as nearly five of every eight dead fragments were collected at PTC. In contrast, one of each eight dead fragments was collected at LP or LA. These results provide circumstantial evidence regarding possible intrinsic and unique factors within each sampled population, e.g., genetic and zooxanthellae composition. Whereby coral fragments from PTC show lower stress tolerance than coral fragments from LA and LP but have high growing capacity. These trends where coral species exhibit higher allocation of resources into growth but less into immune competence, making them more susceptible to perish from diseases or abrupt environmental changes, have been extensively documented [48]. However, intraspecific level has never been documented. Therefore, further genetic studies using coral individuals from different populations are needed to comprehend the potential effects of genetic variability and stress tolerance.

As in previous studies, A. cervicornis exhibits an impressive growth capacity. Fragments grew nearly seven times their original size in the eleven months of the study, (i.e., average growth rates ranging from 0.02 to $0.20 \mathrm{~cm}$ per day), with some colonies growing 30 times their original size. Growth rates reported here are among the highest, if not the highest ever, reported for A. cervicornis fragments reared in suspended farms. For instance, our average daily growth was over 2.3 times higher than those reported by Lirman et al. [25] 
from the Dominican Republic and by Georgen et al. [23] in Florida. And between 3 to 7 times higher than those reported in Puerto Rico [31], Florida [15,49] and Jamaica [50].

The site of fragment collection seen to have great influence on coral fragment growth. Overall, mean MGRs from fragments collected at PTC were significantly higher (e.g., $0.371 \mathrm{~cm} /$ day $)$ than those from fragments collected at LP and LA $(0.354 \mathrm{~cm} /$ day and $0.273 \mathrm{~cm} /$ day respectively), Figure 6 . This pattern was observed at all depths, suggesting that coral from PTC have greater metabolic capacity to grow at three different depths that coral fragments from LA and LP. The contrary could be interpreted with fragments collected at LA, as fragments collected from this site showed the lowest mean MGRs. Overall, these results suggest that surviving corals from PTC have higher tolerance to changing environmental conditions than coral from LA and LP. The differences in acclimatization capacity may be likely linked to distinct genetic heritages among the donor populations $[49,51]$ and or by environmental memory originated through epigenetic modifications [52].

Growth was also influenced by depth. The deeper the fragments were placed, the slower their growth rates were. In fact, growth was nearly $24 \%$ higher in fragments from shallower farms when compared to fragments from deeper farms. These results coincided with previous studies that also reported differences in growth based on water depth. For instance, Baker and Weber [53], working with Orbicella annularis [54], observed that linear and mass growth varies with depth, with colonies in deeper areas showing reduced calcification and thereby, less growth when compared to those in shallow areas. Highsmith [55] also recorded a decrease in the linear and mass growth of Favia pallida, Goniastrea retiformis, and Porites lutea corals with a water depth increase in the Pacific. Huston [56] reached similar conclusions in seven reef-building species (Agaricia agaricites, Orbicella annularis, Montastraea cavernosa, Porites porites, P. astreoides, Colpophyllia natans, and Siderastrea siderea) in Discovery Bay, Jamaica. Furthermore, a decrease in growth rates with increases in water depth has also been detected on gorgonian corals [57] and algae [58], among other photosynthetic organisms. Therefore, an increase in depth (and consequently a decrease in light availability) will cause a decrease in photosynthesis and growth rates in most zooxanthellate corals due to a reduction in the resources allocated to growth $[56,59]$. However, see contrasting results for example from Torres et al. [60] where A. cervicornis colonies were transplanted to deeper zones grew more apparently due to a reduction in UV radiation causing a significant reduction in the production of UV-absorbing compounds and consequently a higher availability of resources for photosynthesis and growth.

We also observed temporal variation in the growth rates, with higher rates during the coldest and lowest LL months (November 2016 to March 2017). This pattern was observed at all depths. This result was striking because we originally thought that coral growth should have been higher during the late spring-early summer months when environmental factors are typically mild, and the stresses induced by these factors have not built up as much as during late summer-early fall. The seasonal growth pattern observed here also coincided with a previous report from naturally occurring A. cervicornis corals at $\mathrm{La}$ Parguera, Puerto Rico [61]. Arguably, the observed seasonal growth patters could be further linked to allocation of resources. For instance, the spring, and early summer, where female gametes of A. cervicornis corals dramatically gain size [62], and water temperature and light levels also rises. Given the naturally resource constraint of $A$. cervicornis, and that, arguably, this period may be of intense resource allocation into reproduction and immunity to withstand the harsh environmental conditions, it would be reasonable to expect fewer resource allocated into growth. The contrary could be argued during the winter season, when corals significantly reduce resource allocation into reproduction and immunity while increasing allocations of resources towards growth.

\section{Conclusions}

Our findings provide useful information for A. cervicornis coral farming practitioners. Currently, most coral farms limit their operations to relatively shallow waters. Our results, however, do not provide strong reasons to move farms from shallow to deep waters, given 
the environmental conditions prevailing during the study and the high farming success based on the benchmarks proposed by [44]. Even though difference in temperature among depths were statistically significant, from a biological standpoint, the magnitude of these variations may not be sufficient to induce the observed growth and mortality differences among deeps. Nonetheless, from a seasonal perspective, temperature plays a paramount role, as seasonal variation in temperature greatly influences growth of coral fragments [61]. On the other hand, light levels, as measured in this study, may have not been adequately measured to clearly determined the real effects of light. Instead, recording UV radiation would have been a better predictor of survival and growth. Nonetheless, the fact that the mortality of fragments was higher in shallower farms, suggest that light levels (as measured here), plays an important role, both at the depth and seasonal levels. Nonetheless, under the forecasted increase in extreme environmental perturbations such as hurricanes, maintaining farms in deeper zones may pay-off. For instance, after the onslaught of Hurricane Irma and María across Puerto Rico in 2017, Toledo-Hernandez et al. [63] and Carrick et al. [64] reported higher $A$. cervicornis survival when fragments were set in farms at $12 \mathrm{~m}$, as compared to fragments set at shallower areas. In fact, coral fragments set at $8 \mathrm{~m}$ and $5 \mathrm{~m}$ in water deep farm perished to the hurricanes. Our study also demonstrates that fragment origin is an important factor to consider when collecting samples. Therefore, we recommend including as many collection sites as possible to ensure differential adaptability capacities among the collected coral individuals. It also essential to track the colonies' origin while following them across the nursing period, selecting those populations with individuals owning higher adaptability capacities i.e., higher survivorship and growth rates, for future restoration projects. Finally, knowing that environmental stressor to corals i.e., temperature and light levels, are at their pick from the late spring to early fall, it would be better to start the farming during late fall-early spring when coral fragment are facing less harmful environmental conditions than during summer. This will optimize the survival and growth of fragments, during the early and most critical phase of farming operations.

Author Contributions: Conceptualization, C.P.R.-D. and C.T.-H.; methodology, C.P.R.-D., C.T.-H. and J.L.S.-G.; software, C.P.R.-D., J.L.S.-G. and B.B.; validation, C.P.R.-D. and B.B.; formal analysis, C.P.R.-D., C.T.-H. and B.B.; investigation, C.T.-H., C.P.R.-D., J.L.S.-G. and B.B.; writing-original draft preparation, C.T.-H. and C.P.R.-D.; writing-review and editing, C.T.-H., C.P.R.-D. and J.L.S.-G.; visualization, C.P.R.-D. and J.L.S.-G.; supervision, C.P.R.-D. and C.T.-H.; project administration, C.T.H. and C.P.R.-D.; funding acquisition, C.T.-H. and C.P.R.-D. All authors have read and agreed to the published version of the manuscript.

Funding: This research was funded by Fundación Toyota, Ford Motor Company Foundation of Puerto Rico, the University of Puerto Rico Sea Grant College Program (NOAA Grant number NA14OAR4170068, Project R-102-1-14). 9 December 2021.

Institutional Review Board Statement: Not applicable.

Informed Consent Statement: Not applicable.

Acknowledgments: We thank Pedro and Nicolas Gómez, Pedro Carmona, José Méndez Rojas, and Frances García for their fieldwork assistance and all the SAM and CESAM members by help in the stablish the coral farms. Also, we want to thank Dany Davila for map design, and Alex MercadoMolina, Alberto Sabat and Heather Moore for critical review of the manuscript. Finally, we like to express our gratitude to the reviewers and editor for their detailed revision.

Conflicts of Interest: The authors declare no conflict of interest. The funders had no role in the design of the study; in the collection, analyses, or interpretation of data; in the writing of the manuscript, or in the decision to publish the results. 


\section{References}

1. Gardner, T.A.; Côté, I.M.; Gill, J.A.; Grant, A.; Watkinson, A.R. Long-term region-wide declines in Caribbean corals. Science 2003, 301, 958-960. [CrossRef] [PubMed]

2. Lopéz-Peréz, A.; Culpul-Magananes, A.; Ahumada-Sempoal, A.; Medina-Rosas, P.; Reyes-Bonilla, H.; Herrero-Perézrul, M.D.; Reyes-Hernández, C.; Lara-Hernández, J. The coral communities of the Isla Marias archipelago Mexico; structure and biogeographic relevance to the Eastern Pacific. Mar. Ecol. 2016, 37, 679-690. [CrossRef]

3. Cramer, K.L.; Jackson, J.B.C.; Donovan, M.K.; Greenstein, B.J.; Korpanty, C.A.; Cook, G.M.; Pandolfi, J.M. Widespread loss of Caribbean acroporid corals was underway before coral bleaching and disease outbreaks. Sci. Adv. 2020, 6, eaax9395. [CrossRef]

4. Pandolfi, J.M.; Bradbury, R.H.; Sala, E.; Hughes, T.P.; Bjorndal, K.A.; Cooke, R.G.; McAdle, D.; McClenachan, L.; Newman, M.J.H.; Paredes, G.; et al. Global trajectories of the long-term decline of coral reef ecosystems. Science 2003, 301, 955-958. [CrossRef]

5. Bellwood, D.R.; Hughes, T.P.; Folke, C.; Nyström, M. Confronting the coral reef crisis. Nature 2004, 429, 827-833. [CrossRef]

6. Miller, M.; Bourque, A.; Bohnsack, J. An analysis of the loss of acroporid corals at Looe Key, Florida, USA: 1983-2000. Coral Reefs 2002, 21, 179-182. [CrossRef]

7. Heron, S.F.; Maynard, J.A.; van Hooidonk, R.; Eakin, C.M. Warming trends and bleaching stress of the World's coral reefs 1985-2012. Sci. Rep. 2016, 6, 38402. [CrossRef] [PubMed]

8. Jokiel, P.L.; Coles, S.L. Response of Hawaiian and other Indo-Pacific Reef corals to elevated temperature. Coral Reefs 1990, 8 , 155-162. [CrossRef]

9. Reaser, J.K.; Pomerance, R.; Thomas, P.O. Coral bleaching and global climate change: Scientific findings and policy recommendations. Conserv. Biol. 2000, 14, 1500-1511. [CrossRef]

10. Frade, P.R.; Bongaerts, P.; Englebert, N.; Rogers, A.; González-Rivero, M.; Hoegh-Guldberg, O. Deep reefs of the Great Barrier Reef offer limited thermal refuge during mass coral bleaching. Nat. Commun. 2018, 9, 1-8. [CrossRef] [PubMed]

11. Ruiz-Diaz, C.P.; Toledo-Hernández, C.; Sabat, A.M.; Marcano, M. Immune response to a pathogen in corals. J. Theor. Biol. 2013, 332, 141-148. [CrossRef]

12. Nieves-González, A.; Ruiz-Diaz, C.P.; Toledo-Hernández, C.; Ramírez-Lugo, J.S. A mathematical model of the interactions between Acropora cervicornis and its environment. Ecol. Model. 2019, 406, 7-22. [CrossRef]

13. Keller, B.D.; Gleason, D.F.; McLeod, E.; Woodley, C.M.; Airame, S.; Causey, B.D.; Friedlander, A.M.; Grober-Dunsmore, R.G.; Johnson, J.E.; Miller, S.L.; et al. Climate change, coral reef ecosystems, and management options for marine protected areas. Environ. Manage. 2009, 44, 1069-1088. [CrossRef]

14. Toledo-Hernández, C.; Yoshioka, P.; Bayman, P.; Sabat, A. Impact of disease and detachment on growth and survivorship of sea fans Gorgonia ventalina. Mar. Ecol. Progr. Ser. 2009, 393, 47-54. [CrossRef]

15. O'Donnell, K.E.; Lohr, K.E.; Bartels, E.; Patterson, J.T. Evaluation of staghorn coral (Acropora cervicornis, Lamarck 1816) production techniques in an ocean-based nursery with consideration of coral genotype. J. Exp. Mar. Bio. Ecol. 2017, 487, 53-58. [CrossRef]

16. Goreau, T.F.; Goreau, N.I. Coral Reef Project-Papers in memory of Dr. Thomas F. Goreau. 17. The Ecology of Jamaican Reefs. II. Geomorphology, Zonation, and Sedimentary Phases. Bull. Mar. Sci. 1973, 23, 399-464.

17. Mercado-Molina, A.E.; Ruiz-Diaz, C.P.; Sabat, A.M. Branching dynamics of transplanted colonies of the threatened coral Acropora cervicornis: Morphogenesis, complexity, and modeling. J. Exp. Mar. Biol. Ecol. 2016, 482, 134-141. [CrossRef]

18. Bruckner, A.W. Proceeding of the Caribbean Acropora Workshop: Potential Application of the U.S. Endangered Species Act as a Conservation Strategy; NOAA Technical Memorandum NMFS-OPR: Sliver Spring, MD, USA, 2002; 199p.

19. Graham, N.A.J.; Nash, K.L. The importance of structural complexity in coral reef ecosystems. Coral Reefs 2003, 32, 315-326. [CrossRef]

20. Yanovski, R.; Nelson, P.A.; Abelson, A. Structural Complexity in Coral Reefs: Examination of a Novel Evaluation Tool on Different Spatial Scales. Front. Ecol. Evol. 2017, 5, 27. [CrossRef]

21. Jackson, J.; Donovan, M.; Cramer, K.; Lam, V. Status and Trends of Caribbean Coral Reefs 1970-2012; Global Coral Reef Monitoring Network, IUCN: Gland, Switzerland, 2014.

22. Aronson, R.B.; Precht, W.F. White-band disease and the changing face of Caribbean coral reefs. Hydrobiologia 2001, 460, 25-38. [CrossRef]

23. Goergen, E.A.; Ostroff, Z.; Gilliam, D.S. Genotype and attachment technique influence the growth and survival of line nursery corals. Restor. Ecol. 2017, 26, 622-628. [CrossRef]

24. Young, C.N.; Schopmeyer, S.A.; Lirman, D. A review of reef restoration and coral propagation using the threatened genus Acropora in the Caribbean and Western Atlantic. Bull. Mar. Sci. 2012, 88, 1075-1098. [CrossRef]

25. Lirman, D.; Schopmeyer, S.; Galvan, V.; Drury, C.; Baker, A.C.; Baums, I.B. Growth Dynamics of the Threatened Caribbean Staghorn Coral Acropora cervicornis: Influence of Host Genotype, Symbiont Identity, Colony Size, and Environmental Setting. PLoS ONE 2014, 9, e107253. [CrossRef]

26. Mercado-Molina, A.; Ruiz-Diaz, C.P.; Sabat, A.M. Demographics and dynamics of two restored populations of the threatened reef-building coral Acropora cervicornis. J. Nat. Conserv. 2015, 24, 17-23. [CrossRef]

27. Rinkevich, B. Restoration strategies for coral reefs damaged by recreational activities: The use of sexual and asexual recruits. Rest. Ecol. 1995, 3, 241-251. [CrossRef]

28. Shaish, L.; Levy, G.; Gomez, E.; Rinkevich, B. Fixed and suspended coral nurseries in the Philippines: Establishing the first step in the gardening concept of reef restoration. J. Exp. Mar. Biol. Ecol. 2008, 358, 86-97. [CrossRef]

29. Levy, G.; Shaish, L.; Haim, A.; Rinkevich, B. Mid-water rope nursery- testing design and performance of a novel reef restoration instrument. Ecol. Eng. 2010, 36, 560-569. [CrossRef] 
30. Baums, I.B.; Baker, A.C.; Davies, W.S.; Grottoli, A.G.; Kenkel, C.D.; Kitchen, S.A.; Kuffner, I.B.; LaJeunesse, T.C.; Matz, M.V.; Miller, M.W.; et al. Considerations for maximizing the adaptive potential of restored coral populations in the western Atlantic. Ecol. Appl. 2019, 29, e01978. [CrossRef] [PubMed]

31. Shafir, S.; Abady, S.; Rinkevich, B. Improved sustainable maintenance for mid-water coral nursery by the application of an antifouling agent. J. Exp. Mar. Biol. Ecol. 2009, 368, 124-128. [CrossRef]

32. Griffin, S.; Spathias, H.; Moore, T.; Baums, I.; Griffin, B.A. Scaling up Acropora nurseries in the Caribbean and improving techniques. In Proceedings of the 12th International Coral Reef Symposio, Cairns, Australia, 9-13 July 2012.

33. Putchim, L.; Thongtham, N.; Hewett, A.; Chansang, H. Survival and growth of Acropora spp. in-water nursery and after transplantation at Phi Phi Islands, Andaman Sea Thailand. In Proceedings of the 11th International Coral Reef Symposium, Fort Lauderdale, FL, USA, 7-11 July 2008.

34. Foo, S.A.; Asner, G.P. Sea surface temperature in coral reef restoration outcomes. Environ. Res. Lett. 2020, 15, 074045. [CrossRef]

35. Bridge, T.C.L.; Hoey, A.S.; Campbell, S.J.; Muttaqin, E.; Rudi, E.; Fadli, N.; Baird, A.H. Depth-dependent mortality of reef corals following a severe bleaching event: Implications for thermal refuges and population recovery [version 3; peer review: 2 approved, 1 approved with reservations]. F1000Research 2014, 2, 187. [CrossRef]

36. Enochs, I.C.; Manzello, D.P.; Carlton, R.; Schopmyeyer, S.; van Hooidonk, R.; Lirman, D. Effects of light and elevated $p \mathrm{CO}_{2}$ on the growth and photochemical efficiency of Acropora cervicornis. Coral Reefs 2014, 33, 477-485. [CrossRef]

37. Therneau, T.M.; Grambsch, P.M. Modeling Survival Data: Extending the Cox Model; Springer: New York, NY, USA, 2000; ISBN 0-387-98784-3.

38. Kohler, K.E.; Gill, S.M. Coral Point Count with Excel extensions (CPCe): A Visual Basic program for the determination of coral and substrate coverage using random point count methodology. Comput. Geosci. 2006, 32, 1259-1269. [CrossRef]

39. Kuznetsova, A.; Brockhoff, P.B.; Christensen, R.H.B. lmerTest Package: Tests in Linear Mixed Effects Models. J. Stat. Softw. 2017, 82, 1-26. [CrossRef]

40. R Core Team. R: A Language and Environmental for Statistical Computing; R Foundation for Statistical Computing: Vienna, Austria, 2014

41. Rowan, R.; Knowlton, N.; Baker, A.C.; Baker, A.; Jara, J. Landscape ecology of algal symbionts creates variation in episodes of coral bleaching. Nature 1997, 388, 265-269. [CrossRef] [PubMed]

42. Marshall, P.A.; Baird, A.H. Bleaching of corals on the Great Barrier Reef: Differential susceptibilities among taxa. Coral Reefs 2000, 19, 155-163. [CrossRef]

43. Morais, J.; Santos, B.A. Limited potential of deep reefs to serve as refuges for tropical southwestern Atlantic corals. Ecosphere 2018, 9, e02281. [CrossRef]

44. Schopmeyer, S.A.; Lirman, D.; Bertels, E.; Gilliem, D.S.; Goergen, E.A.; Griffin, S.P.; Johnson, M.E.; Lustic, C.; Maxwell, K.; Walter, C.S. Regional restoration benchmarks for Acropora cervicornis. Coral Reefs 2017, 36, 1047-1057. [CrossRef]

45. Muir, P.R.; Marshall, P.A.; Abdulla, A.; Aguirre, J.D.; Muir, P.R. Species identity and depth predict bleaching severity in reef-building corals: Shall the deep inherit the reef? Proc. R. Soc. B 2017, 284, 20171551. [CrossRef]

46. Riegl, B.; Piller, W.E. Possible refugia for reefs in times of environmental stress. Int. J. Earth. Sci. 2003, 92, 520-531. [CrossRef]

47. Glynn, P.W. Coral reef bleaching: Facts, hypotheses, and implications. Glob. Chang. Biol. 1996, 2, 495-509. [CrossRef]

48. Palmer, C.V.; Traylor-Knowles, N. Towards an integrated network of coral immune mechanisms. Proc. R. Soc. B Biol. Sci. 2012, 279, 4106-4114. [CrossRef] [PubMed]

49. Drury, C.; Manzello, D.; Lirman, D. Genotype and local environment dynamically influence growth, disturbance response and survivorship in the threatened coral, Acropora cervicornis. PLoS ONE 2017, 12, e0174000. [CrossRef] [PubMed]

50. Quinn, N.J.; Kojis, B.L. Evaluationg the potential of natural preproductiona dnarticical techniques to increase Acropora cervicornis population at Discovery Bay, Jamaica. Rev. Biol. Trop. 2010, 54, 105-116.

51. Bowden-Kerby, A.; Quinn, N.; Stennet, M.; Mejia, A. Acropora cervicornis Restoration to Support Coral Reef Conservation in the Caribbean. NOAA Coast. Zone 2012, 5, 7-10.

52. Hackerrott, S.; Martell, H.A.; Eirin-López, J.M. Coral environmental memory: Causes, mechanisms, and consequences for future reefs. Trends Ecol. Evol. 2021, 36, 1011-1016. [CrossRef]

53. Baker, P.A.; Weber, J.N. Coral growth rate: Variation with depth. Earth Planet. Sci. Lett. 1975, 27, 57-61. [CrossRef]

54. Budd, A.F.; Fukami, H.; Smith, N.D.; Knowlton, N. Taxonomic classification of the reef coral family Mussidae (Cnidaria: Anthozoa: Scleractinia). Zool. J. Linn. Soc. 2012, 166, 465-529. [CrossRef]

55. Highsmith, R.C. Coral growth rates and environmental control of density banding. J. Exp. Mar. Biol. Ecol. 1979, 37, 105-125. [CrossRef]

56. Huston, M. Variation in coral growth rates with depth at Discovery Bay, Jamaica. Coral Reefs 1985, 4, 19-25. [CrossRef]

57. Kinzie, R.A., III. The zonation of West Inidan gorgonians. Bull. Mar. Sci. 1973, 23, 93-155.

58. Birkeland, $\mathrm{C}$. The importance of rate of biomass accumulation in early successional stage of benthic communities to the survival of coral recruit. In Proceedings of the Third International Coral Reef Symposium, Miami, FL, USA, 1 January 1977; University of Miami: Miami, FL, USA; Volume 1, pp. 5-21.

59. Kahng, S.E.; Watanabe, T.K.; Hu, H.M.; Watanabe, T.; Shen, C.C. Moderate zooanthellate coral growth rates in the lower photic zone. Coral Reef 2020, 39, 1273-1284. [CrossRef]

60. Torres, J.L.; Armstrong, R.A.; Corredor, J.E.; Gilbes, F. Physiological Responses of Acropora cervicornis to Increased Solar Irradiance. Photochem. Photobiol. 2007, 83, 839-850. [CrossRef] [PubMed] 
61. Weil, E.; Hammerman, N.M.; Becicka, R.L.; Cruz-Motta, J.J. Growth dynamics in Acropora cervicornis and A. prolifera in southwest Puerto Rico. PeerJ 2020, 8, e8435. [CrossRef] [PubMed]

62. Bernardo, V.-A.; Colley, S.B.; Hoke, S.M.; Thomas, J.D. The reproductive seasonality and gametogenic cycle of Acropora cervicornis off Broward County, Florida, USA. Coral Reefs 2006, 25, 110-122.

63. Toledo-Hernández, C.; Ruiz-Díaz, C.P.; Hernández-Delgado, E.; Suelimán, S. Devastation of 15-year old community-based coral farming and reef restoration sites in Puerto Rico by major Hurricanes Irma and María. Carb. Nat. 2018, 53, 1-6.

64. Carrick, J.; Lustic, C.; Lirman, D.; Schopmeyer, S.; Bartels, E.; Burdeno, D.; Dahlgren, C.; Galvan, V.M.; Gilliam, D.; Goergen, L.; et al. Hurricane Impacts on Reef Restoration: The Good, Bad and the Ugly. In Activate Coral Restoration, Techniques for a Changing Planet, 1st ed.; Vaughan, D.E., Ed.; J. Ross Publishing: Fort Lauderdale, FL, USA, 2021; Volume 1, pp. $483-510$. 